\title{
Study of the swelling pressure of coals and coal charges in the coking process
}

\author{
Tatiana Cherkasova ${ }^{1 *}$, Nikita Krasulin ${ }^{1}$, Aleksandr Nevedrov ${ }^{1}$, Andrey Papin ${ }^{1}$, and \\ Sergey Subbotin ${ }^{1}$ \\ ${ }^{1}$ T.F. Gorbachev Kuzbass State Technical University, 650000, Russian Federation
}

\begin{abstract}
The maintenance of furnaces is one of the most important problems for by-product coke production. Swelling pressure is one of the least studied factors affecting the lining of coke furnace walls. The results of studies of the swelling pressure of PJSC "Koks" feedstock coal are presented in this paper. Research has been carried out to identify the dependence of the swelling pressure on the coal quality indicators, estimated during the incoming control of the central plant laboratory of PJSC "Koks". The plastic properties of PJSC "Koks" feedstock coals were studied using Gieseler plastometer. The relationship between the swelling pressure and the maximum coal fluidity is revealed.
\end{abstract}

\section{Introduction}

Swelling pressure is the coal charge expansion pressure. This pressure arises when coking coals during the most intense devolatilization [1-5]. For many coals, the time interval of the coking process, characterized by the maximum devolatilization rates, coincides with the moment of formation of the maximum amount of plastic mass. Therefore, the evolved gaseous products, meeting the resistance of the plastic mass, cause it to swell $[6,7]$.

High pressure on the coking chamber walls leads to their accelerated destruction. This, in turn, entails the chamber shutdown for repairs. Damage to several walls may require relining of entire coking chambers; in case of large damage, it may be necessary to reline the entire coke furnace battery [8].

\section{Materials and methods}

Studies to determine the swelling pressure of coals and coal charges of PJSC "Koks" coke-chemical production feedstock were carried out at T.F. Gorbachev Kuzbass State Technical University, together with PJSC "Koks". The tester for determining

\footnotetext{
* Corresponding author: ctg.htnv@kuzstu.ru
} 
the coal swelling pressure is an electric furnace lined with lightweight fireclay bricks with heating elements located at the front and rear of the chamber and a retort made of stainless steel and lined with lightweight fireclay bricks. One of the retort walls is movable and is a stainless plate through which the swelling pressure is transmitted from the coal charge, char and coke to the weight sensor. The sensor readings are recorded by the computer. The result of the test is the plot of the swelling pressure $\left(\mathrm{P}_{\text {swell }}\right)$ expressed in kg against test duration. The study results are presented in Table 1 .

Table 1. Coal study results

\begin{tabular}{|l|l|l|l|l|l|}
\hline Coal rank & $\begin{array}{l}\mathbf{P}_{\text {swell, }} \\
\mathbf{k g}\end{array}$ & $\mathbf{y}, \mathbf{m m}$ & $\begin{array}{l}\mathbf{V} \text { daf, } \\
\mathbf{\%}\end{array}$ & $\mathbf{\mathbf { V } ^ { \text { daf } } / \mathbf { y }}$ & $\begin{array}{l}\mathbf{F}, \\
\mathbf{d d} / \mathbf{m i} \\
\mathbf{n}\end{array}$ \\
\hline K rank - coking coal (JSK Polyany) & 0,84 & 13 & 26,95 & 2,073077 & 242 \\
\hline $\begin{array}{l}\text { GZh rank - gas fat coal } \\
\text { (Abashevskaya Mine) }\end{array}$ & 1,34 & 18 & 37 & 2,055556 & 659 \\
\hline $\begin{array}{l}\text { GZh rank - gas fat coal (Uvalnaya } \\
\text { Mine) }\end{array}$ & 1,76 & 21 & 37,75 & 1,797619 & 19669 \\
\hline $\begin{array}{l}\text { K rank - coking coal (JSK Polyany } \\
\text { VIP) }\end{array}$ & 0,67 & 15 & 25,85 & 1,723333 & 158 \\
\hline $\begin{array}{l}\text { K rank - coking coal (Koksovy Area } \\
\text { Open Pit) }\end{array}$ & 0,58 & 15 & 23,2 & 1,546667 & 333 \\
\hline $\begin{array}{l}\text { K rank - coking coal (Severnaya } \\
\text { Mine) }\end{array}$ & 0,79 & 15 & 21,2 & 1,413333 & 858 \\
\hline $\begin{array}{l}\text { Zh rank - fat coal (Yeruakovkaya } \\
\text { Mine) }\end{array}$ & 2,3 & 28 & 33,4 & 1,192857 & 30778 \\
\hline Zh rank - fat coal (Tikhova Mine) & 7,25 & 34 & 32,89 & 0,967353 & 37943 \\
\hline
\end{tabular}

\section{Results and discussion}

Studies were carried out to identify the relationship between the swelling pressure of coals and coal charges and their quality characteristics such as swelling index according to IGI-DMet "Ivs", vitrinite reflectance " $\mathrm{R}_{0}$ ", total vitrinite content " $\mathrm{V}_{\mathrm{t}}$ ", dry ash-free basis volatiles " $V^{\text {daf", }}$ plastometric indexes " $y$ " and " $\mathrm{x}$ ".

From the presented plot it follows that the swelling pressure does not depend on these values. It is necessary to consider the relationship between the swelling pressure and a set of indicators.

There is a theory that the ratio of dry ash-free basis volatiles to the plastic layer thickness $\left(\mathrm{V}^{\mathrm{daf}} / \mathrm{y}\right)$ correlates with the swelling pressure of coals and coal charges [9]. Based on this theory, $P_{\text {swell }}$ against $V^{\text {daf } / y ~ w a s ~ p l o t t e d ~(s e e ~ F i g . ~ 1) . ~}$

As a result of further work, the relationship between the swelling pressure and the ratio of volatiles $\left(\mathrm{V}^{\mathrm{daf}}, \%\right)$ to the plastic layer thickness $(\mathrm{y}, \mathrm{mm})$ was found. This relationship is shown in Fig. 1. From Fig. 1 it follows that with an increase in the $\mathrm{V}^{\mathrm{daf}} / \mathrm{y}$ ratio from 1 to 1.5 , the swelling pressure decreases; with a further increase in the ratio, the swelling pressure grows insignificantly, the maximum value of the swelling pressure is observed when the $\mathrm{V}^{\text {daf }} / \mathrm{y}$ ratio is close to unity. 


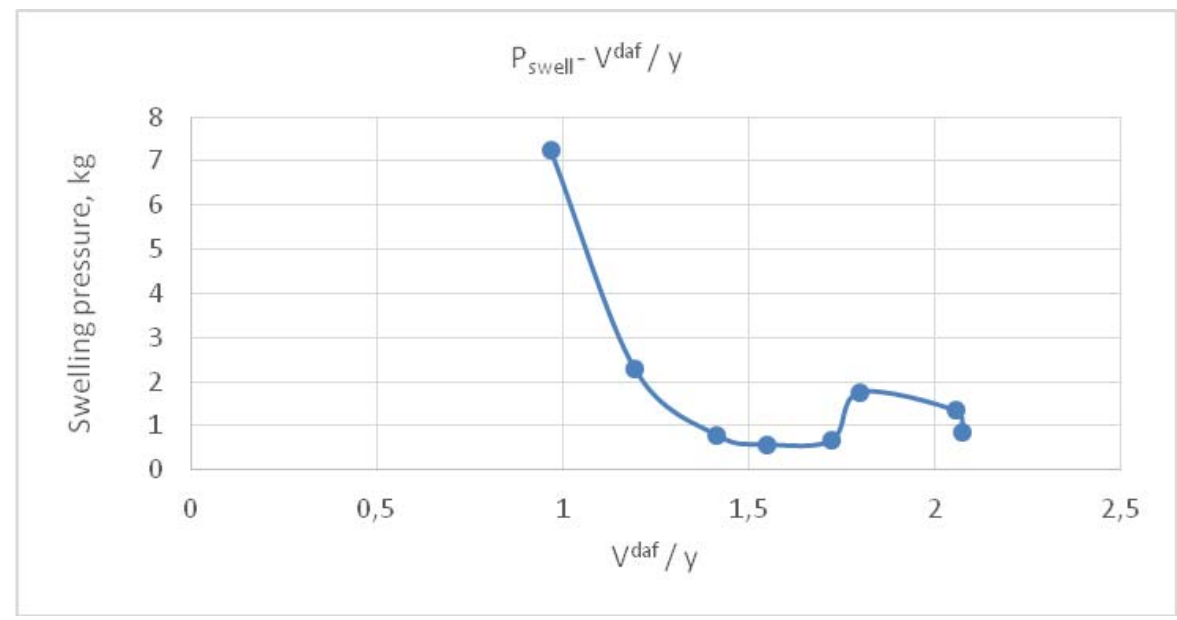

Fig. 1. Plot of the swelling pressure against the ratio of dry ash-free basis volatiles to the plastic layer thickness

A ratio close to unity is typical for $\mathrm{Zh}$ rank coals; these coals are distinguished by a high index of the plastic layer thickness, which characterizes the ability of coal to pass into a plastic state. Thus, the more plastic mass is formed, the greater the swelling pressure.

Another indicator characterizing the amount of plastic mass is the maximum Gieseler fluidity (State Standard GOST R 4247-2010). Maximum fluidity is measured in dial divisions per minute $(\mathrm{F}, \mathrm{dd} / \mathrm{min})$. The Gieseler fluidity for the tested coals is presented in Table 1. Based on the data obtained, the swelling pressure of coals against their fluidity was plotted.

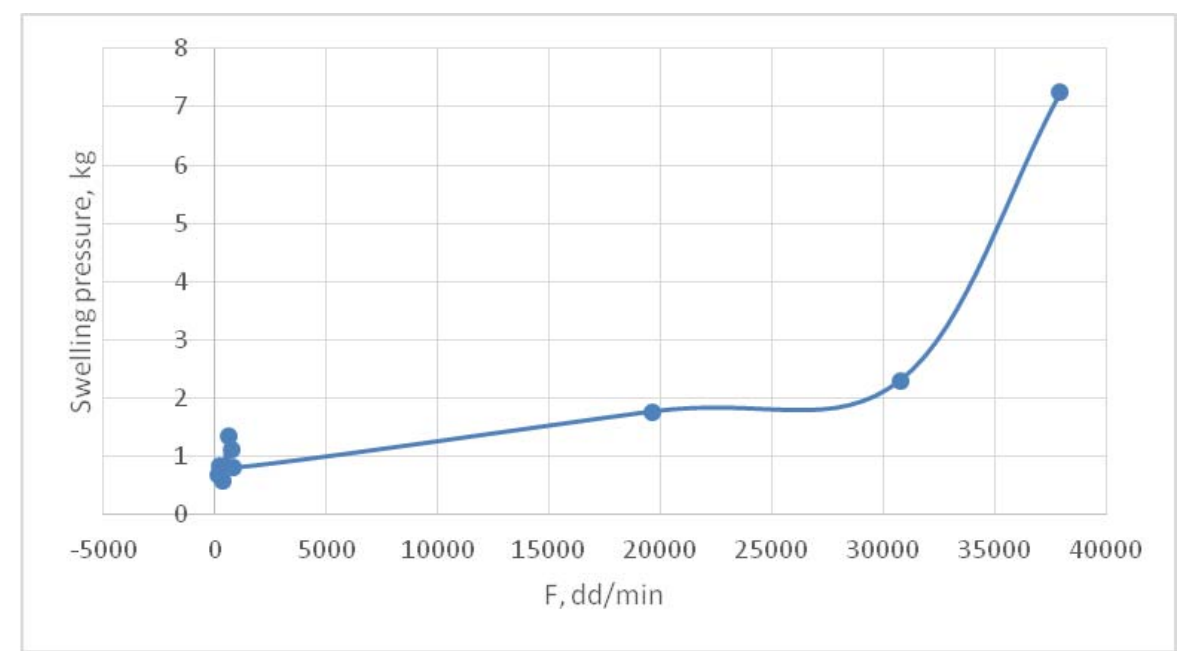

Fig. 2. Plot of the swelling pressure against maximum Gieseler fluidity

The most fluid coals generate a higher swelling pressure due to the formation of a less gas-permeable mass [10-14]. 
GZh and Zh rank coals have the highest maximum fluidity. The maximum fluidity of coals of other ranks rarely exceeds $1000 \mathrm{dd} / \mathrm{min}$.

The increased swelling pressure of $\mathrm{Zh}$ rank coals is caused by a suitable ratio of plastic mass to the volatile content. With this ratio, the plastic mass is sufficient to keep the swelling gases in the charge.

In parallel with the study of the swelling pressure of coals, work was carried out to study the charge (mixtures of coals) measuring their swelling pressure. Work was carried out to forecast the swelling pressure of the charge, in which the swelling pressure of the charge was calculated assuming the additivity of the maximum pressure of its components. The swelling pressure of the charges differs significantly from the computed one.

When studying the swelling pressure of the charge, a hypothesis was put forward about the influence of each coal on the swelling pressure of the charge. So, its essence is that each coal affects the swelling pressure to the extent corresponding to the share of a given coal in the charge (the additivity law). Earlier it was said that the swelling pressure does not follow the additivity law, but the approach to this issue was incorrect and revised.

Two-component mixtures of the Koksovy Area Open Pit coal and the S.D. Tikhov Mine coal were considered in increments of $25 \%$ (Fig. 3-5) to support the charge additivity hypothesis.

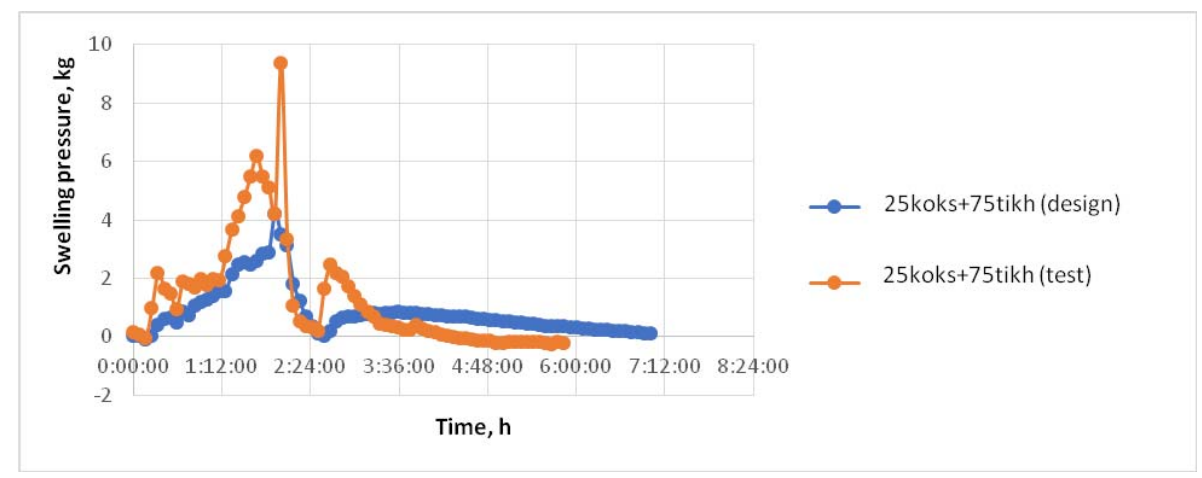

Fig. 3. Plot of the swelling pressures against the time they were reached for the design mixture $(25 \%$ - the Koksovy Area Open Pit coal $+75 \%$ - the S.D. Tikhov Mine coal) and for the test one 


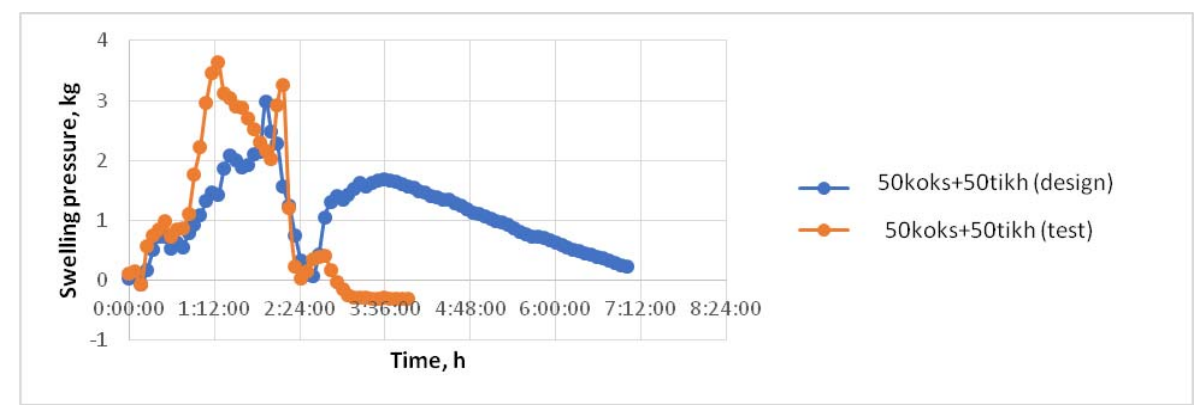

Fig. 4. Plot of the swelling pressures against the time they were reached for the design mixture $(50 \%$ - the Koksovy Area Open Pit coal $+50 \%$ - the S.D. Tikhov Mine coal) and for the test one

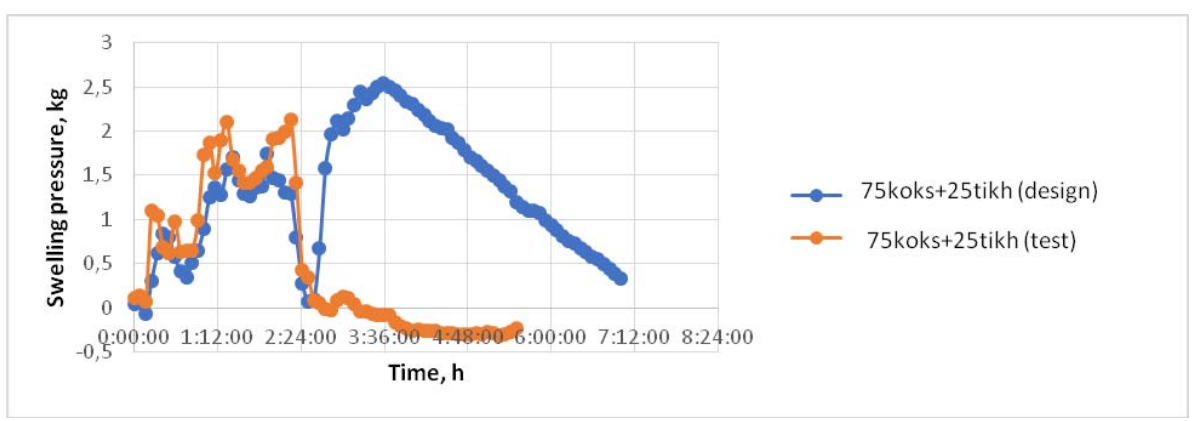

Fig. 5. Plot of the swelling pressures against the time they were reached for the design mixture $(75 \%$ - the Koksovy Area Open Pit coal $+25 \%$ - the S.D. Tikhov Mine coal) and for the test one

The plots show that the calculated values are a little bit lower than the values obtained experimentally, but the general trend in the of swelling pressure dynamics and general curve outlines remain the same, an coincidence of some peaks is observed.

Studies of the swelling pressure of coal charges of the following compositions were carried out:

1) $20 \%$ - GZh rank coal (Uvalnaya Mine); $20 \%$ - Zh rank coal (Tikhova Mine); 30\% - K rank coal (Koksovy Area Open Pit); 15\% - K rank coal (JSK Polyany); $15 \%$ - the mixture of $\mathrm{KO}$ and $\mathrm{KC}$ rank coal (Beryozovskaya Concentration Plant).

2) $20 \%$ - GZh rank coal (Uvalnaya Mine); $20 \%$ - Zh rank coal (Tikhova Mine); 30\% - K rank coal (JSK Polyany VIP); 15\% - K rank coal (JSK Polyany); $15 \%$ - the mixture of $\mathrm{KO}$ and KC rank coal (Beryozovskaya Concentration Plant).

3) $20 \%$ - GZh rank coal (Abashevskaya Mine); 20\% - Zh rank coal (Tikhova Mine); 30\% - K rank coal (JSK Polyany VIP); 15\% - K rank coal (JSK Polyany); $15 \%$ - the mixture of $\mathrm{KO}$ and $\mathrm{KC}$ rank coal (Beryozovskaya Concentration Plant).

4) $20 \%$ - GZh rank coal (Abashevskaya Mine); 20\% - Zh rank coal (ш. Ерунаковская); 30\% - K rank coal (JSK Polyany VIP); 15\% - K rank coal (JSK Polyany); $15 \%$ - the mixture of $\mathrm{KO}$ and $\mathrm{KC}$ rank coal (Beryozovskaya Concentration Plant). 
5) $20 \%$ - GZh rank coal (Uvalnaya Mine); 20\% - Zh rank coal (Tikhova Mine); 30\% - K rank coal (JSK Polyany VIP); 15\% - K rank coal (JSK Polyany); $15 \%$ - KO rank coal (Butovskaya Mine).

The plots of the swelling pressures of coal charges against the time they were reached are presented in figures 6-10.

The computed swelling pressure of coal charges 1, 2, 3, 4, 5 was plotted on the basis of the plots of the swelling pressure of PJSC "Koks" feedstock coal. It was assumed that the curves of the swelling pressure of charges, obtained by the experimental and computational methods, will coincide.

Analysis of the presented plots showed that the contours and pressure peaks of the curves obtained by experimental and computational methods coincide when they are superimposed on each other. Thus, plotting, it is possible to predict the swelling pressure of the charge. Based on the plots, it can be concluded that the coals practically do not interact with each other as part of the charge; the stages of decomposition and coking of each coal in the charge being in the same temperature range as for pure coals.

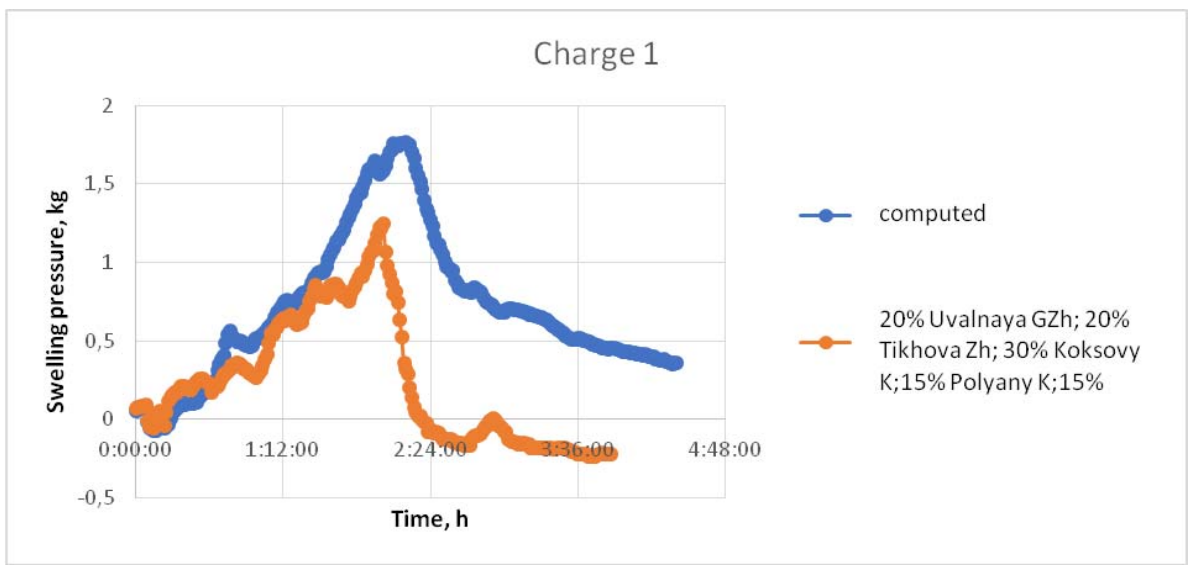

Fig. 6. Plots of the computed and observed swelling pressures against the time they were reached for the charge 1

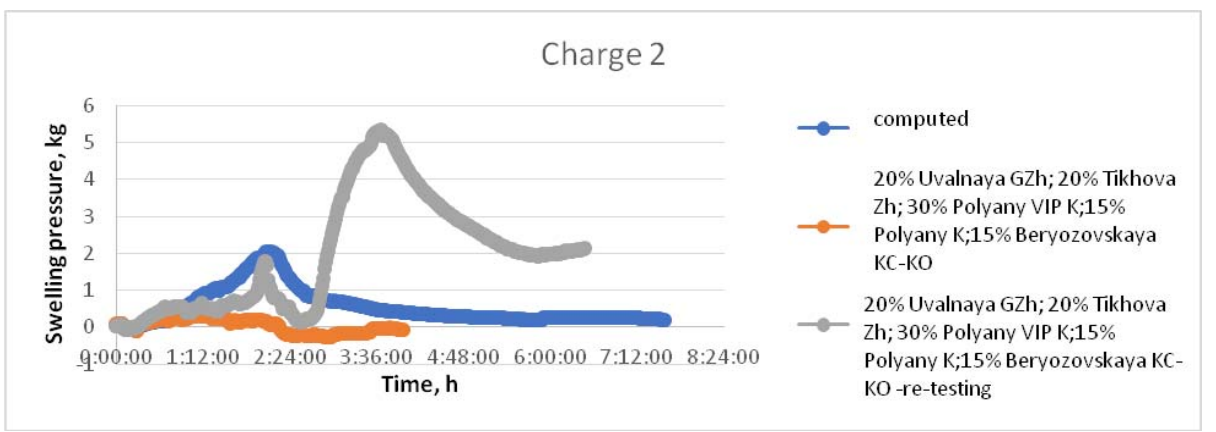

Fig. 7. Plots of the computed and observed swelling pressures against the time they were reached for the charge 2 


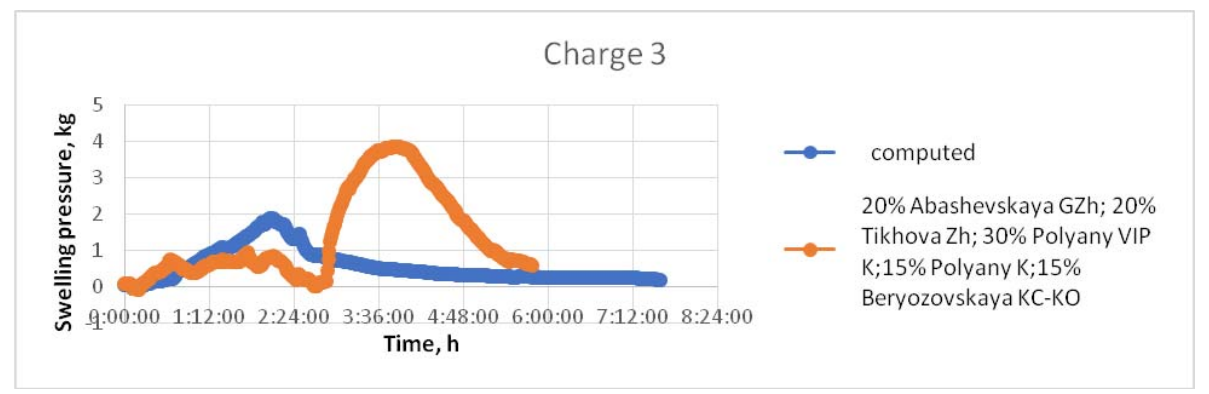

Fig. 8. Plots of the computed and observed swelling pressures against the time they were reached for the charge 3

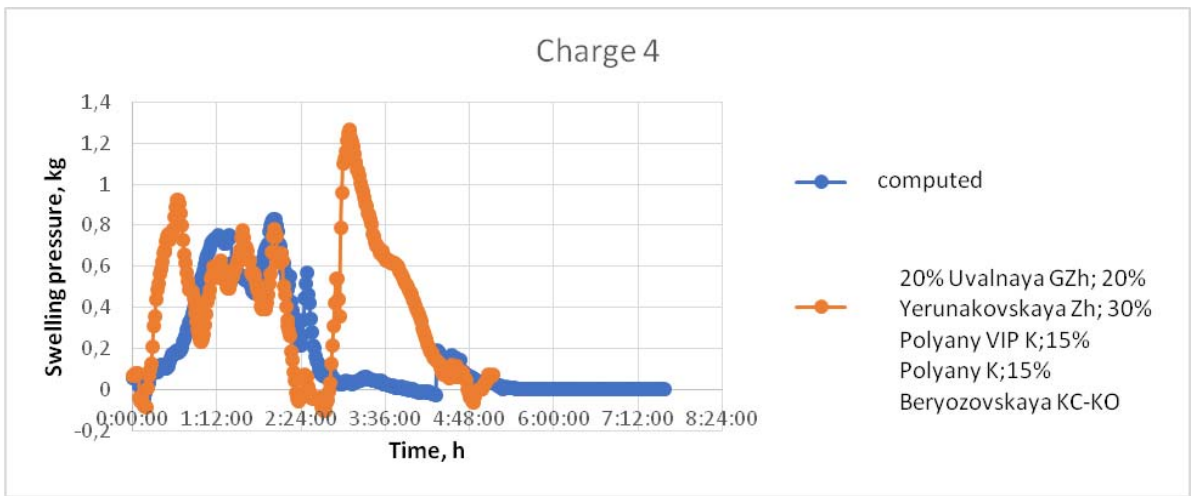

Fig. 9. Plots of the computed and observed swelling pressures against the time they were reached for the charge 4

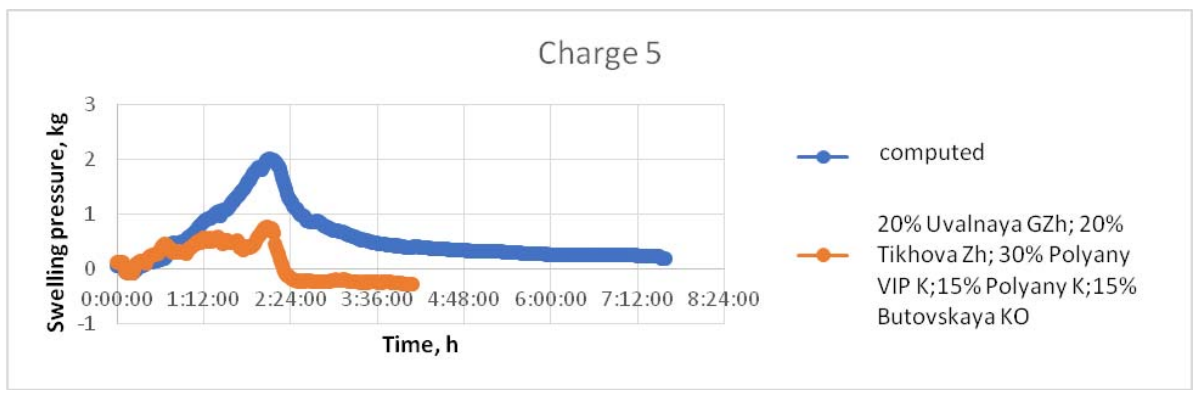

Fig. 10. Plots of the computed and observed swelling pressures against the time they were reached for the charge 5

\section{Conclusion}

The swelling pressure of coals and coal charged depends on the ratio of dry ash-free basis volatiles to the plastic layer thickness.

The swelling pressure of coal depends on maximum Gieseler fluidity. With an increase of maximum fluidity, the swelling pressure increases. 
The swelling pressure of coal charges follows the additivity law. The computed swelling pressure of coal charges is plotted based on the plots of the swelling pressure of PJSC "Koks" feedstock coal. Additivity is observed not at the maximum or minimum pressure values but at each point of the plot.

\section{References}

1. S. Nomura, T. Arima, A. Dobashi, K. Doi, 51:9, 1425 (2011)

2. T.G. Callcott. BHP Technical Bulletin, 23:2, 49 (1979)

3. V. Krebs, J.F. Mareche, G. Furdin, D. Dumay.Fuel, 73:12, 1904 (1994)

4. E.O. Shmeltser, V.P. Lyalyuk, V.P. Sokolova, D.V. Miroshnichenko, Coke and chemistry, 56:12, 31 (2017)

5. G. Nashan, W. Rohde, K. Wessiepe, Proc. of the 4th ECIC.Paris., l, 646 (2000)

6. H. Durselen, J. Janicka. GlUckauf-Forschungshefte, 48:4, 208 (1987)

7. J.-F. Geny, J.-M. Duchene, Cokemaking Int., 4, 21 (1992)

8. H.W. Jackman, R.J. Helfinstine, Blast Furnace and Steel Plant, 2, 119 (1969)

9. R. Loison, P. Foch, Revue de 1'industrie minerale, 1, 1 (1964)

10. M. Whysall, Iron and Steel, 4, 411 (1972)

11. H. Echterhoff, Brennstoff-Chemie, 10, 294 (1968)

12. J. Makowski, Koks, Smola, Gas. 1, 1 (1973)

13. A. Furusawa, T. Nakagawa, Y. Maeno, I. Komaki, ISIJ Int, 38:12, 1320 (1998)

14. W.J. Lee, Y.K. Lee, RIST J of R\&D (South Korea), 14:1, 107 (2000) 